\title{
Spillover Effects of HIV Foreign Aid on the Delivery of Maternal and Child Health Services in Nigeria: 2008 - 2018
}

Sunny lbeneme ( $\square$ ibenemes@who.int)

University of Texas Health Science Center at Houston https://orcid.org/0000-0002-6703-4649

Kevin Croke

Harvard University T H Chan School of Public Health

Humphery Karamagi

World Health Organization Regional Office for Africa: Organisation mondiale de la Sante pour Afrique

Jesse Bump

Harvard University T H Chan School of Public Health

Joseph Okeibunor

World Health Organization Regional Office for Africa: Organisation mondiale de la Sante pour Afrique

Research

Keywords: Global Health Initiatives, Health Systems, HIV Financing, Maternal and Child Health, Nigeria

Posted Date: July 22nd, 2021

DOI: https://doi.org/10.21203/rs.3.rs-688583/v1

License: (c) (7) This work is licensed under a Creative Commons Attribution 4.0 International License. Read Full License 


\section{Abstract}

Background

This study expands the current body of knowledge by investigating the impact of the Global Health Initiatives (GHI) on the Nigerian health system. Using robust multilevel analytic approaches, this study examined system-wide impacts of foreign aid on the Nigerian health system- a country that has witnessed substantial Development Assistance for Health disbursements in the last two decades, yet has one of the worst maternal and child health indices globally. Most of the health aid to Nigeria has been for HIV programs; and has sparked debates among stakeholders. Critics have asserted the possibility that HIV aid might not be working and could have had unintended negative consequences on the delivery of non-HIV services. Others maintained that such prioritized attention to HIV could have had a crowding-out or negative spillover effect on the delivery of other health programs in Nigeria. Thus, the focus of this study is to ascertain the nature of the spillover effect of HIV aid on the delivery of maternal and child health services in Nigeria

Results

This study identified that donor HIV financing to Nigeria increased up to 2012, and decreased steadily afterwards between 2008 - 2018 . This was suggested to be linked to PEPFAR priority shift to health systems strengthening in the second round of their funding cycle. This study also identified a negative spillover effect of HIV-specific aid on the delivery of non-HIV services, and is suggested to be attributed to the prioritized attention given to HIV programs by global health systems.

Conclusions

Study findings provide systematic evidence to inform policy on the frameworks for developing a national roadmap for the effective alignment of GHIs' coordinating mechanisms with national health priorities. Future studies should explore the effects of the Development Assistance for Health among low- and middle-income countries including Nigeria to provide evidence for policy, and substantiate how the growing interests in health systems strengthening is overcoming vertical programs and fostering systemic improvements. Government should identify turnaround strategies to strengthen Nigerian health systems for the Sustainable Development Goals, and formulate policies that improve the effectiveness of GHIs in Nigeria.

\section{Background}

Donor support for healthcare service delivery in developing countries has been remarkable with unprecedented gains on certain fronts including HIV services $[1,2]$. Health aid to Nigeria has been on the increase since the 1990s. The annual Development Assistance for Health (DAH) disbursements to Nigeria increased from $\$ 10.1$ billion in 2008 to $\$ 16.1$ billion in 2017 [3]. The attention given to HIV programs has been particularly striking compared to other programs. HIV donor support to Nigeria doubled as a proportion of DAH from 1990 to 2000, and HIV aid increased over fourfold between 1992 and 2005 notwithstanding competing national priorities $[4,5,6]$. Three Global Health Initiatives (GHIs) including the US President's Emergency Plan for AIDS Relief, the Global Fund to Fight AIDS, Tuberculosis and Malaria, and the World Bank Multi-AIDS Project have been responsible for most HIV financing in Nigeria [7].

In Nigeria, there are concerns that HIV financing have continued to overshadow and could have had negative spillover effects on the delivery of other health programs including Maternal and Child Health (MNCH) services. In 2014, MNCH diseases contributed about $45 \%$ of the total Disability Adjusted Life Years (DALYS) lost to diseases compared to $6.3 \%$ for HIV, yet only $0.5 \%$ of all health-specific foreign aid was earmarked for MNCH services in Nigeria. This contrasts with an enormous $32 \%$ for HIV programs [3]. This imbalance between disease burden and financing could impact priorities and skew attention to diseases with greater funding. Thus, services for specific diseases could be scaled-up at the expense of overall health systems development. While DAH may have strengthened national health systems appreciably, there are concerns that the increasing HIV funding may have negatively impacted the delivery of non-HIV services [8].

This study expands the current body of knowledge by investigating the impact of the GHI's HIV funding on the Nigerian health system. It evaluated the characteristics and trend of aid disbursements to Nigeria, as well as investigated the nature of the spillover effect of HIV funding on the delivery of MNCH services in Nigeria. Using multilevel analytic approaches, this study investigated what the impact of spending an extra dollar on HIV programs will have on the delivery of $\mathrm{MNCH}$ services in Nigeria. Findings from this study have opportunities to inform the formulation of policies that improve the effectiveness of the GHIs in Nigeria. This could facilitate the development of a national roadmap for the effective alignment of GHIs' coordinating mechanisms with national health priorities.

Over the years, HIV programs in Nigeria have received unprecedented priorities by donors, and has sparked debates among stakeholders. HIV programs have received a disproportionate share of aid relative to its disease burden [5]. Public opinion surveys in most contexts have ranked support for HIV programs low relative to other health priorities, even among HIV patients and their network members [9]. These conversations have continued to gain momentum as there are concerns that donor support for HIV programs could be crowding-out or displacing support for other health programs $[1,6]$. However, the prioritized attention given to HIV programs has been explained on the grounds of human rights; as HIV is a pandemic, and requires focused emergency interventions [10].

On the contrary, advocates of HIV programs have continued to lobby and push for increased HIV funding. They argue that allocating additional funding to HIV programs could strengthen existing health systems and improve the overall health service delivery [11]. Given that HIV patients routinely seek care at health facilities for antiretroviral medication refills, viral load checks and other related services; thus, keeping them healthier and reducing their need for, and net use of services could free-up spaces for the delivery of services to other patients [12].

Donor-driven HIV programs have recorded great successes across the globe including Nigeria. By the end of 2015, an estimated 7.5 million people were receiving antiretroviral medications, and many others were receiving HIV support and preventive services [13]. However, despite massive flow of HIV aid to 
global health systems, there have been increasing debates regarding the effectiveness of aid in general including the influx of new HIV funding. Critics have asserted the possibility that HIV aid might not be working and could have had unintended negative consequences on the delivery of non-HIV services [12, 14,

15]. In addition, other researchers have tested the robustness of many empirical studies and have found in real terms that aid has not been effective as it has weak associations with public policy, democracy and poverty $[16,17]$.

There is also an increasing debate in Nigeria about whether the scale-up investments in national health programs including HIV programs is producing the desired result of self-reliance or not. Critics found a negative association, and relate this to the interplay of socioeconomic, political, and cultural factors that play-out at the national level to affect aid effectiveness $[18,19]$. They maintained that the government has abdicated most of its responsibilities to donors, and have mismanaged most funds meted for health programs [20]. Inequitable distribution and allocation of donor-driven resources stemming from corruption impact the delivery of health programs, thereby increasing aid ineffectiveness [16]. Aid works best when applied in a good policy environment. Thus, it has been argued that aid is conditionally effective with such considerations to robust public policy, transparent governance, and accountable financial management [18].

That notwithstanding, the delivery of HIV programs in most contexts have been parallel with the delivery of other health services at the national level especially in view of scaling HIV programs. The delivery of HIV programs requires large human capital for clinical and administrative roles. However, human resources for health (HRH) in Nigeria has been considered inadequate [2]. Thus, reallocating HRH to HIV programs might leave fewer healthcare workers available to carry out other health systems' functions. In addition, the systemic vertical approach to most HIV programs further widens the gap and exacerbates the dearth of the health sector workforce. Thereby, weakening national health systems and impacting outcomes [21, 22, 23].

While multiple studies have documented the impact of aid on health outcomes for specific cases, it is not immediately clear the nature of the spillover effect of HIV aid disbursements on the delivery of non-HIV services in Nigeria. Our objective was to quantify what the impact of spending an extra dollar on HIV services will be on the delivery of $\mathrm{MNCH}$ services in Nigeria. We chose Nigeria because of data availability, including the presence of substantial aid disbursements to Nigeria. Prior studies have used qualitative methodologies to investigate this question in Nigeria [18, 20, 24]. Other researchers have also used quantitative approaches to evaluate this concept among facilities, districts, and regions [1, 6, 8]. Kotasadam et al. (2017) documented that the presence of active aid projects among impoverished Nigeria communities reduced infant mortality. In Malawi, aid improved self-reported quality of life including reductions in the prevalence of malaria and diarrheal diseases [26]; and in Uganda, aid reduced the overall disease burden and severity [27]. However, the focus of this study is to ascertain the nature of the spillover effect of HIV aid on the delivery of MNCH services in Nigeria. Given that the impacts of most HIV programs are likely to be felt at the national level; there is a need to investigate this further for the Nigerian health system.

Findings from this study have opportunities to inform the formulation of policies that improve the effectiveness of the GHIs in Nigeria, and therefore acts as a reference for policymakers, development organizations and other researchers. This study has opportunities to inform the formulation of improved service delivery frameworks from a healthier population perspective. Thus, using robust analytic approaches, this study investigated system-wide impacts of HIV aid disbursements on multiple MNCH outcomes in Nigeria. It evaluated the nature of the spillover effect of HIV funding on the delivery of MNCH services in Nigeria. We relied on robust multilevel regression models to estimate the relationships between HIV aid disbursements and population health measures.

\section{Materials And Methods}

\section{Sources of Data: Development Assistance for health}

Data on health aid to Nigeria was obtained from the Institute for Health Metrics and Evaluation's country and recipient development assistance for health (IHME DAH) database for the period 2008-2018. Aid data from the IHME is categorized into different thematic areas including HIV programs, non-HIV health services, and MNCH services, among others. Aid for non-HIV services is the difference between aid for all health programs and aid for HIV services, which were all calculated on a per capita basis in constant 2018 US dollars. The IHME database was chosen because it contains aid disbursements and not commitments from both public and private sources including foundations. In addition, multilateral donors are tracked using information obtained directly from the donors instead of using data obtained from secondary sources [3]. To reflect actual aid disbursements and not commitments, this study focused on aid flows available from 2008 up to 2018 .

\section{Maternal Health Outcomes}

Data on maternal services were obtained from the National Demographic Health Survey (NDHS) conducted in Nigeria during 2008-2018 [28]. The NDHS is a nationally representative household survey that provides data for a wide range of monitoring and impact evaluation indicators in the areas of health, nutrition, and population. Information related to antenatal and delivery care of mothers while pregnant, as well as postnatal care and other related health data were obtained from the NDHS database. De-identified data for the mother of each of these children were also included in the NDHS database. For each child born within each of the five years of the surveys, the mother reports whether she sought antenatal care (ANC) when pregnant of that baby; whether her blood pressure was checked during ANC or not, whether she received blood test during ANC or not, whether she received urine test during ANC or not, and whether a skilled birth attendant was present during delivery or not.

\section{Child Health Outcomes}

Data on child health measures for Nigeria were obtained from two rounds of the NDHS conducted in Nigeria in 2013 and 2018 . Datasets from these two surveys were merged to form a single database to allow analyses across time. For each child within this round of survey, the mother was asked for the immunization history of the child, and this was verified by checking the immunization cards [28]. The NDHS database is chosen ahead of the WHO and UNICEF joint reporting database because of its granularity especially in collecting MNCH indicators. The joint WHO and UNICEF database represents 
administrative data reported by countries on vaccination rates, and may not help this study identify year-to-year variations [29]. However, the NDHS database has inherent limitations of recall and reporting bias especially for retrospective data that relies on memories of past events [28].

Immunization rates were defined as the proportion of children (0-59 months) that received the third dose of diphtheria-pertussis-tetanus (DPT3). This is one of the recommended vaccines for infants, according to the National Program on Immunization, which is Nigeria's version of the global Expanded Program on Immunization [30]. Conceptually, DPT3 coverage is used as a proxy for measuring the performance of routine immunization programs [31]. The units of observation are children (0-59 months) for the previous two NDHS surveys which is done every five years. Indicators for child's health were obtained from the children's recode file which is a subset of the NDHS. This file has records for every child born to an eligible woman (15-49 years), and contains data on immunization rates including the receipt of zinc medications among other indicators. Zinc is given to children to reduce the frequency, duration and severity of diarrhea diseases as part of the Integrated Management of Childhood Illnesses recommended by the WHO. The WHO recommends $20 \mathrm{mg}$ daily doses of zinc medications for children, and 10mg daily doses for infants less than six months with acute diarrhea for 10-14 days' period. This helps to reduce the severity of diarrhea diseases and prevent further reoccurrences for up to 3 months [32].

Nigeria has one of the highest infant mortality rates in the world, with about $20 \%$ of these deaths attributable to vaccine preventable diseases [33]. Thus, integrated management on childhood illnesses including childhood immunization should be a national priority. Nigeria also has one of the worst maternal mortality rates globally with an estimated 814 deaths/100,000 live births in 2015 [30]. Therefore, maternal health constitutes a major burden in Nigeria and should deserve major attention.

\section{Covariates}

Data for the annual health expenditures by the Nigeria government, expressed as per capita total expenditure on health in purchasing power parity international dollars was obtained from the WHO's Global Health Observatory [34]. Data for other MNCH measures were obtained from the NDHS including sex of child, country geopolitical region, place of residence (rural or urban), family wealth index, parents' religion, mothers' age at delivery, mothers' educational status, whether mother received at least one ANC visit while pregnant with the index child, and the presence of skilled birth attendant at the delivery of index child [28]. Analyses was done for approximately 99330 children born in Nigeria between 2008 and 2018. 2008 was used as the beginning point for these analyses because information for the first birth cohort was available and captured in the 2013 demographic health survey [28].

\section{Econometric Analysis}

Study empirical analytics compares outcomes in a given year with aid disbursements in the previous year, while controlling for annual time trends. This becomes necessary considering the variations in the magnitude and timing for aid disbursements to Nigeria to identify the impacts of aid on the delivery of non-HIV services. The disbursement to all health programs, including HIV, non-HIV, and MNCH services were estimated separately to check for differential impacts of different forms of aid. Conceptually, aid for HIV is earmarked for HIV programs. Thus, an association between aid disbursements for HIV programs and the delivery of $\mathrm{MNCH}$ services would suggest that HIV programs are generating broader system-wide effects. A positive association would suggest a strengthening effect, while a negative association would suggest a displacement (crowding-out) effect.

Study analytics was done using STATA/SE version 16.0 (StataCorp, College Station, TX, USA). Multilevel regression analyses of the associations between the independent variables and $\mathrm{MNCH}$ measures were done, since the outcome measures of interest were binary. Multilevel regression models (Equation-1) were used to estimate the effect of HIV aid on the uptake of non-HIV health services in Nigeria, while controlling for individual-level determinants of service uptake. Multilevel models allow for the simultaneous examination of the effects of group-level and individual-level variables on individual-level outcomes while accounting for the non-independence of observations within groups. This approach enables the modelling of data in which the times of the measurements vary from subject to subject [35].

$Y_{i t}=\beta_{0}+X_{i t}+Z_{t}+\mu_{i t}$ (1)

Where $Y_{i t}$ is a binary variable coded 'yes' or 'no' indicating whether any given child/pregnant mother $i$ received a particular health service at a time $t$ or not. $X$ represents a set of household-level factors that impact service delivery at the individual-level including sex of child, country geopolitical region, whether the place of residence is rural or urban, family wealth index, mother's age at delivery, mother's educational status, whether mother received at least one ANC visit while pregnant with the index child, and the presence of skilled birth attendant at the delivery of index child. $Z$ represents country-level aggregate measures at time $t$, and includes study explanatory variables of interest- aid disbursements to Nigeria expressed in constant \$US per capita per year, and the annual health expenditures by the Nigeria government, expressed as per capita total expenditure on health in purchasing power parity international dollars in a given year. $\beta_{0}$ is the intercept, while $\mu_{i t}$ is the error term.

Thus, this study looked separately at the effects of HIV aid, MNCH aid, and non-HIV non-MNCH aid (other aid) on the outcomes of interest to assess for differential effects of different aid categories on the delivery of $\mathrm{MNCH}$ services in Nigeria. The coefficient and sign on HIV aid indicate the presence or absence of a spillover effect on $\mathrm{MNCH}$ services which could be positive or negative.

\section{Results}

\section{Figure 1: Health aid disbursement per capita for HIV and other health programs}

Aid for non-HIV non-MNCH services (other aid) was comparable to aid for HIV services for most period until 2013, after which HIV-specific aid disbursements declined steadily unlike that of 'other aid' which continued to rise, such that by 2018 'other aid' approximately doubled HIV-specific aid. In contrast, aid for $\mathrm{MNCH}$ services stayed mostly flat for the entire period and only began to rise slowly from 2013. 
While $85 \%$ of HIV/AID expenditure in Nigeria was funded by external donors, the external funding for routine immunization services in Nigeria was put at $65 \%$ (Figs. 2 and 3). This demonstrates donors' priority to HIV funding in Nigeria [7, 36].

Source: National AIDS Spending Assessment (NASA) for the period 20017-2018 [7].

Source: Nigeria Comprehensive Multi Year Plan, costing and financing tool [36].

Source: WHO Global health observatory data repository: Health expenditure ratios data by country [34].

Table 1

Summary Statistics for categories of health aid disbursements in Nigeria

\begin{tabular}{|lccc|}
\hline Categories & Mean & Minimum & Maximum \\
\hline Aid disbursement per capita (2008-2018) & & & \\
\hline All health aid (\$) & 13.995 & 12.043 & 14.418 \\
\hline HIV aid (\$) & 12.896 & 10.763 & 13.557 \\
\hline MNCH aid (\$) & 12.992 & 12.151 & 13.661 \\
\hline Other aid (\$) & 13.409 & 11.498 & 13.991 \\
\hline
\end{tabular}

Table 1 represents the summary statistics of the dependent variables. Over the period of study analyses, aid for HIV services was averagely equal to aid for $\mathrm{MNCH}$ services on a per capita basis.

Table 2

Summary Statistics for principal independent variables

\begin{tabular}{|ll|}
\hline MNCH Health Outcomes & $\%\left(n^{\mathbf{a}}\right)$ \\
\hline Received DPT-3 Vaccine & \\
\hline Yes & $40.44(26364)$ \\
\hline No & $59.56(38$ 816) \\
\hline Child Received Zinc & \\
\hline Yes & $21.90(2363)$ \\
\hline No & $78.10(8428)$ \\
\hline BP Checked during Pregnancy & \\
\hline Yes & $93.16(42144)$ \\
\hline No & $6.84(3168)$ \\
\hline Urine test done during Pregnancy & \\
\hline Yes & $84.59(39170)$ \\
\hline No & $15.41(7134)$ \\
\hline Blood test done during Pregnancy & \\
\hline Yes & $85.82(39735)$ \\
\hline No & $14.18(6568)$ \\
\hline
\end{tabular}

Table 2 represents the summary statistics of the main explanatory variables. Over the period of analysis of this study; averagely the percentage of children that received DPT-3 and Zinc were $40 \%$ and $22 \%$ respectively. The average percentage of women that received BP check, urine test and blood test during ANC visits were $93 \%, 85 \%$ and $86 \%$ respectively. Summary statistics tables for the control variables are also documented (Appendix 1 ).

Table 3 represents the result of the simple logistic regression models. It highlights the effect of US\$1 of health aid per capita on the delivery of MNCH services at the individual-levels in Nigeria from 2008-2018. It gives the effects as log odds from simple logistic regression models. Conceptually, study data for children/mothers are nested within years such that all children/mothers that received a particular health services in Nigeria in a given year are mapped to have the same health aid and government expenditure. Thus, the effects were modeled as a two-level random intercept logistic regression. However, since the coefficients from the multilevel model were very similar and the appropriate test indicated that the multilevel model is mostly not needed, only the results from the simple logistic regression are reported. However, the multilevel regression outputs are documented (Appendix 2). 
Table 3

Effect of US\$1 of health aid per capita on the delivery of MNCH services at the individual-level in Nigeria, 2008-2018: Simple logistic regression analyses

\begin{tabular}{|c|c|c|c|c|c|c|c|c|c|}
\hline \multirow{2}{*}{$\begin{array}{l}\text { Health aid } \\
\text { category }\end{array}$} & \multicolumn{2}{|l|}{ DPT, third dose } & \multicolumn{2}{|c|}{ Child Received Zinc } & \multicolumn{2}{|l|}{ BP Checked } & \multicolumn{2}{|l|}{ Blood Test } & Urine Test \\
\hline & $\begin{array}{l}\log (\mathrm{OR})(95 \% \\
\mathrm{Cl})\end{array}$ & $\begin{array}{l}\mathrm{p}- \\
\text { value }\end{array}$ & $\begin{array}{l}\log (O R)(95 \% \\
\mathrm{Cl})\end{array}$ & $\begin{array}{l}\text { p- } \\
\text { value }\end{array}$ & $\begin{array}{l}\log (O R)(95 \% \\
\mathrm{Cl})\end{array}$ & $\begin{array}{l}\mathrm{p} \text { - } \\
\text { value }\end{array}$ & $\begin{array}{l}\log (O R)(95 \% \\
\mathrm{Cl})\end{array}$ & $\begin{array}{l}\text { p- } \\
\text { value }\end{array}$ & $\begin{array}{l}\log (O R)(95 \% \\
\mathrm{Cl})\end{array}$ \\
\hline
\end{tabular}

\begin{tabular}{|c|c|c|c|c|c|c|c|c|c|c|}
\hline HIV aid & $\begin{array}{l}-0.20(-0.23 \text { to } \\
-0.17)\end{array}$ & $<_{0.001}^{<}$ & $\begin{array}{l}-0.38(-0.51 \text { to } \\
-0.26)\end{array}$ & $\hat{0.001}$ & $\begin{array}{l}-0.52(-0.66 \text { to } \\
-0.38)\end{array}$ & $\hat{0} .001$ & $\begin{array}{l}-0.45(-0.55 \text { to } \\
-0.35)\end{array}$ & $\hat{0} .001$ & $\begin{array}{l}-0.35(-0.43 \\
\text { to }-0.26)\end{array}$ & 0.010 \\
\hline MN & $\begin{array}{l}-1.00(-0.13 \text { to } \\
-0.07)\end{array}$ & $\hat{0} .001$ & $\begin{array}{l}1.56 \\
(1.42 \text { to } 1.70)\end{array}$ & ¿́.001 & & $\hat{0} .001$ & & $\hat{0} .001$ & $\begin{array}{l}0.25 \\
(0.19 \text { to } 0.31)\end{array}$ & $\hat{0} .001$ \\
\hline Other & $\begin{array}{l}-0.11(-0.13 \text { to } \\
-0.08)\end{array}$ & $\hat{0} .001$ & $\begin{array}{l}2.13 \\
(1.91 \text { to }-2.34)\end{array}$ & 0.001 & $\begin{array}{l}0.33 \\
(0.25 \text { to } 0.41)\end{array}$ & $\hat{0} .001$ & $\begin{array}{l}0.28 \\
(0.21 \text { to } 0.34)\end{array}$ & ¿́.001 & $\begin{array}{l}0.04(-0.20 \text { to } \\
0.29)\end{array}$ & 0.723 \\
\hline
\end{tabular}

Control variables used in each regression were gender of the child; geopolitical region of the country; religion of parents; place of residence; family wealth index; age of the mother at delivery of the index child; mothers' educational status; number of ANC visit by mother while pregnant with the index child; presence of skilled birth attendant at the delivery of the index child; the government health expenditure per capita in purchasing power parity international \$.

Table 4

Marginal effect of US\$1 of health aid per capita on the delivery of MNCH services at the individual-level in Nigeria, 2008-2018

\begin{tabular}{|c|c|c|c|c|c|c|c|c|c|c|}
\hline \multirow{2}{*}{$\begin{array}{l}\text { Health aid } \\
\text { category }\end{array}$} & \multicolumn{2}{|l|}{ DPT, third dose } & \multicolumn{2}{|c|}{ Child Received Zinc } & \multicolumn{2}{|l|}{ BP Checked } & \multicolumn{2}{|l|}{ Blood Test } & \multicolumn{2}{|l|}{ Urine Test } \\
\hline & $\begin{array}{l}\text { Marginal effect } \\
(95 \% \mathrm{Cl})\end{array}$ & $\begin{array}{l}\mathrm{p}- \\
\text { value }\end{array}$ & $\begin{array}{l}\text { Marginal effect } \\
(95 \% \mathrm{Cl})\end{array}$ & $\begin{array}{l}\text { p- } \\
\text { value }\end{array}$ & $\begin{array}{l}\text { Marginal effect } \\
(95 \% \mathrm{Cl})\end{array}$ & $\begin{array}{l}\mathrm{p}- \\
\text { value }\end{array}$ & $\begin{array}{l}\text { Marginal effect } \\
(95 \% \mathrm{Cl})\end{array}$ & $\begin{array}{l}\text { p- } \\
\text { value }\end{array}$ & $\begin{array}{l}\text { Marginal } \\
\text { effect ( } 95 \% \\
\mathrm{Cl})\end{array}$ & $\begin{array}{l}\mathrm{p} \text { - } \\
\text { value }\end{array}$ \\
\hline HIV aid & $\begin{array}{l}-0.05(-0.05 \text { to } \\
-0.04)\end{array}$ & $\dot{0} 001$ & $\begin{array}{l}-0.07(-0.09 \text { to } \\
-0.05)\end{array}$ & $\hat{0.001}$ & $\begin{array}{l}-0.03(-0.04 \text { to } \\
-0.02)\end{array}$ & <. 001 & $\begin{array}{l}-0.05(-0.07 \text { to } \\
-0.05)\end{array}$ & $\dot{0} 001$ & $\begin{array}{l}-0.05(-0.06 \\
\text { to }-0.03)\end{array}$ & $\hat{0.001}$ \\
\hline $\mathrm{MNCH}$ aid & $\begin{array}{l}-0.02(-0.03 \text { to } \\
-0.02)\end{array}$ & $\hat{0} .001$ & $\begin{array}{l}0.26 \\
(0.24 \text { to } 0.28)\end{array}$ & $\hat{0} .001$ & $\begin{array}{l}0.03 \\
(0.02 \text { to } 0.03)\end{array}$ & ¿. 001 & $\begin{array}{l}0.05 \\
(0.04 \text { to } 0.05)\end{array}$ & $\hat{0.001}$ & $\begin{array}{l}0.03 \\
(0.02 \text { to } 0.04)\end{array}$ & $\hat{0.001}$ \\
\hline Other aid & $\begin{array}{l}-0.03(-0.03 \text { to } \\
-0.02)\end{array}$ & $\hat{0} .001$ & $\begin{array}{l}0.34 \\
(0.31 \text { to } 0.38)\end{array}$ & <. 001 & $\begin{array}{l}0.03 \\
(0.01 \text { to } 0.02)\end{array}$ & $\hat{0} .001$ & $\begin{array}{l}0.03 \\
(0.03 \text { to } 0.04)\end{array}$ & $\dot{0} 001$ & $\begin{array}{l}0.02 \text { ( }(0.01 \text { to } \\
0.03)\end{array}$ & $\hat{0.001}$ \\
\hline
\end{tabular}

Control variables used in each regression were gender of the child; geopolitical region of the country; religion of parents; place of residence; family wealth index; age of the mother at delivery of the child; mothers' educational status; number of ANC visit by mother while pregnant with the index child; presence of a skilled birth attendant at the delivery of the child; the government health expenditure per capita in purchasing power parity international $\$$ for the previous year

Table 4 represents the marginal effect table. It shows the average marginal effect of US\$1 per capita increase in aid on the delivery of MNCH services based on the simple logistic regression analyses. Conceptually, the marginal effect (Table 4) determines the probability that a given child/woman received a particular health service, whereas the log odds (Table 3) represent a log transformation of the ratio of the probability of the child/mother being able to receive a particular service over the probability of them not to have received that particular service.

As represented in Table 4, US\$1 increase in HIV aid per capita was associated with a decrease in the probability of receipt of MNCH services by 3-7\%. Blood pressure check decreased by $3 \%(p<0.001)$; DPT third dose decreased by $5 \%(p<0.001)$; blood test decreased by $5 \%(p<0.001)$; urine test decreased by $5 \%$ ( $p$ $<0.001)$, and receipt of zinc decreased by $7 \%(\mathrm{p}<0.001)$. In contrast, $\mathrm{MNCH}$ aid and 'Other aid' were mostly significantly associated with an increase in the probability that a given child/pregnant woman in Nigeria received the listed services except for the receipt of DPT-3.

\section{Discussion}

This study demonstrates that HIV aid had a negative spillover effect on the delivery of MNCH services in Nigeria between 2008 and 2018 . If the delivery of maternal and child health services were taken as proxies to represent non-HIV health services in Nigeria, then study identified negative spillover effects could be considered to have had a crowding-out (weakening) effect on the Nigerian health systems. Given that donors prioritize HIV programs, this negative spillover effect deserves further attention and should inform roundtable discussions on focused system-wide approaches to sustainable health systems financing among Low- and Middle-Income Countries (LMICs). Donors and policy-makers are to use study results for planning purposes in-view of consolidating sustainable investments with system-wide impacts [23].

Conceptually, spillover effect means that health sector investments in one health service area has a knock-on effect on the delivery of other health services or programs in the same country. Spillover effects can arise from inherent health systems' competitions including but not limited to Human Resources for Health $(\mathrm{HRH})$, administration and finance among others [21]. Over the years, the Nigerian health sector has had a critical shortage of manpower [2]. This status quo is

Page 6/13 
worsened by the drift of expert national health professionals to international donor jobs for better remunerations, and has resulted in fewer HRH to deliver national health mandates [2]. The dearth of $\mathrm{HRH}$ to drive and sustain delivery of essential health services have consequences to introduce systemic negative spillover effects. In addition, experienced human resource leaderships are needed to coordinate donor activities in countries. These groups are also lost to international jobs for better wages, thereby widening the gap in $\mathrm{HRH}$ available to coordinate strategic health mandates. Focusing donor resources to a particular disease area could lead to a diversion of attention of health leadership to prioritized disease areas with attendant systemic negative spillover effects $[21,23]$.

Another possible mechanism that could introduce systemic spillover effects is competition for finances among health systems. For instance, In Nigeria, immunization campaigns have been driven by external donors [36]. However, immunization programs continue to experience substantial funding gaps which impacts national coverage rates [36, 37]. Chima and Franzini (2016) reported that donor-prioritized HIV financing had a negative spillover effect on the provision of immunization services in Nigeria between 1997-2003. Beyond 2003 up to the time of this study, there was no scientific evidence to prove that HIV financing continued to have a negative spillover effect on the delivery of immunization services in Nigeria. However, this study showed that since 2013 , HIV programs were no longer prioritized by donors even as the negative spillover effects persist. This study also demonstrated that MNCH aid was associated with a decrease in the probability that a given child received DPT3 vaccine. Thus, identified negative spillover effect suggests that poor MNCH aid (Fig. 1), could have contributed to poor coverage rates, and could have contributed to the declaration of a national emergency on routine immunization in Nigeria in 2017 [38].

Findings from this study are consistent with study from Grepin's multi-country study among eight Sub-Saharan African countries, though with variations on data sources for foreign aid and MNCH indicators [6]. Study findings were also consistent with study by Chima and Franzini (2016) who did a single country analyses using the IHME aid data and the NDHS, though with variations on child health indicators. The use of the IHME and NDHS data sources facilitated differential assessments of the impacts of HIV and $\mathrm{MNCH}$ aid on topical $\mathrm{MNCH}$ outcomes. Focusing on a single country enables this study to remove possible confounders that could arise from varying country contextual factors. To increase the robustness and generalizability of this study, we ran simple logistic and multi-level models as necessary.

The increase in HIV aid to tackle HIV in Nigeria steadily rose up to 2013, and declined afterwards (Fig. 1). This could possibly be linked to the several GHIs that collectively financed most HIV/AIDS programs in Nigeria [7]. However, this study identified a steady decline of HIV financing from 2013-2018. This could possibly be linked to the GHIs policy change especially that of PEPFAR: While the first round of PEPFAR funding (2003-2008) placed emphasis on scaling strategic HIV interventions; the emphasis of the second round of PEPFAR funding (2008-2013) was on health systems strengthening. Thus, PEPFAR funding were diverted to systemic improvements, and possibly suggests the decline in HIV financing from 2013. This diversion of attention in part could explain the negative spillover effect observed in this study. Furthermore, it is possible that the effects of the first round of PEPFAR funding which ended in 2008 got complemented by grants from related official development assistance which rather increased aid flow up to 2013 [39].

Although the GHIs brought the needed resources to public health especially among the LMICs; yet many studies have documented that it burdened fragile health systems among LMIC economies [12,24]. The GHIs has a track record of using silos approaches to achieve their mandate by scaling-up treatment for specific diseases of global interest. Most investments are vertical and program-specific with limited policy buy-in, and lack evidence for positive systemic effects [23]. On many occasions, parallel systems were created for HIV programs by the GHIs in an attempt to address global health interests and produce results for the Sustainable Development Goals (SDGs), or to overcome weak health systems seen among most LMICs. Such duplication of efforts and vertical approaches undermines system-wide effects and improvements [22, 23].

Spillover mechanisms in the face of vertical programs could precipitate strengthening or weakening of health systems [8]. The WHO have used evidencebased approaches to address and align the impacts of the GHIs with national health priorities. Through positive synergistic strategies, the WHO has built capacity, competency and knowledge on the mode of engagement and interactions between the GHIs and national health systems for effective results. Such approaches place emphasis on the establishment of regular reviews, capacity improvements and communities of practice to align investments with national priorities through robust planning, implementation and review mechanisms [40].

Though this study attempted to control possible confounders, yet there are possibilities that other unobserved factors could impact study findings. For instance, issues on national immunization programs are well documented in literature [36, 37]. In Nigeria, MNCH services are collectively funded by the Federal, State, and Local Government Areas (LGAs). Notable bottlenecks in the delivery of MNCH services in Nigeria are lack of fund to effectively deliver $\mathrm{MNCH}$ services; unavailability and inadequate access to $\mathrm{MNCH}$ services; low prioritization of $\mathrm{MNCH}$ services by health sector leaderships especially at the grassroots; and misalignment of priorities between donors and governmental leaderships [19]. For instance, the national health sector leadership have a strong political will to support the procurement and delivery of vaccines to States, but do not have the powers to oversee vaccine disbursements to the LGAs and the rural primary health centers. They do not have control over change management at the State and LGA levels [36].

Despite interesting findings from this study, yet this study had some limitations. There was no reliable data to compare annual DAH flows to State health spending in Nigeria, nor was there any reliable data on the breakdown of government expenditure by disease areas to evaluate governments' reaction to donor priorities. Thus, this study could not map variations in HIV aid to States with HIV prevalence rates across States of Nigeria. Future studies should spatially map HIV donor funding to states with HIV prevalence rates across Nigerian states. There was also a lack of detailed government MNCH expenditure to explore trends and patterns of associations with outcomes of interest. Thus, future studies should use granular policy data to explore government's response to donor priorities and map these to outcomes of interests. In addition, there were also issues related to the IHME DAH database. This database uses statistical imputation approaches to impute missing data. It did not give the exact time a particular fund was disbursed. Given that most grants are multi-layered in nature, it would have been good to know when a particular fund is allocated, disbursed and timelines of such funds including expiration dates. This study looked at the impact of aid disbursement in a given year on the delivery of health services in the following year. Oftentimes, there is a time lag between fund 
allocation, disbursement and availability for recipient countries. Thus, using longitudinal retrospective research methodologies, future studies should search through larger volumes of data to capture trends, patterns and associations.

\section{Conclusions}

This study identified that donor HIV financing to Nigeria increased up to 2012, and decreased steadily afterwards during the study period. This was suggested to be linked to PEPFAR priority shift to health systems strengthening in the second round of their funding cycle. This study also identified a negative spillover effect of HIV-specific aid on the delivery of non-HIV services, and is suggested to be attributed to the attention given to HIV programs by the global health systems. Future studies should explore the effects of DAH among LMICs including Nigeria to provide evidence for policy, and substantiate how the growing interests in health systems strengthening is overcoming vertical programs and fostering systemic improvements.

\section{Abbreviations}

DAH: Development Assistance for Health; GHI Global Health Inititiartives; UHC: Universal Health Coverage; SDGs: Sustainable Development Goals; MNCH: Maternal and Child Health; DALYS: Disability Adjusted Life Years; LMICs: Low- and Middle-Income Countries; NDHS: National Health Demographic Survey; IHME: Institute for Health Metrics and Evaluation; HRH: Human Resources for Health; WHO: World Health Organization; ANC: Antenatal Care; DPT: DiphtheriaPertussis-Tetanus; LGA: Local Government Areas.

\section{Declarations}

\section{Ethical approval and consent to participate}

Not applicable

\section{Consent for Publication}

Not applicable

\section{Availability of data and materials}

The dataset generated and/or analyzed during the current study are available in the National Demograhic Health Survey [http://www.measuredhs.com/WhatWe-Do/Survey-Types/DHS.cfm]; the Institute for Health Metrics and Evaluation [http://ghdx.healthdata.org/record/ihme-data/development-assistance-healthdatabase-1990-2019]; and the World Health Organization's Global Health Observatory [http://apps.who.int/gho/data/node.main.75?lang=en]

\section{Competing interests}

The authors declare that they have no competing interests

\section{Funding}

Not applicable

\section{Authors' contribution}

$\mathrm{SI}, \mathrm{JO}$, and KC wrote the first draft of the manuscript. SI, HK, KC and JB analyzed and interpreted the study dataset. SI, HK, KC and JO developed study framework. All authors read and approved the final draft of the manuscript for publication.

\section{Acknowledgement}

We acknowledge the support from the Takemi Program in International Health for the support during the Fellowship year. This research was completed during the Fellowship year as part of the requirements for completing the Takemi Fellowship. We also acknowledge the contributions and support from Emily Coles for her support during the Fellowship year and in getting this manuscript ready. We are solely responsible for the views expressed in this manuscript, as it does not reflect the views and policies of authors affiliating institutions.

\section{References}

1. Kruk ME, Jakubowski A, Rabkin M, Elul B, Friedman M, El-Sadr W: PEPFAR programs linked to more deliveries in health facilities by African women who are not infected with HIV. Health Affairs. 2012;31:7.

2. Onwujekwe O, Ezumah N, Mbachu C, Obi F, Ichoku H, Uzochukwu B, Wang H: Exploring effectiveness of different health financing mechanisms in Nigeria; what needs to change and how can it happen? BMC Health Services Research. 2019; 19:661.

3. Institute for Health Metrics and Evaluation: Development Assistance for Health Country and Regional Recipient Level Database $1990-2019$. Institute for Health Metrics and Evaluation (IHME), Seattle, United States 2010. http://ghdx.healthdata.org/record/ihme-data/development-assistance-healthdatabase-1990-2019. Accessed January 11, 2021.

4. Shiffman J: Has donor prioritization of HIV/AIDS displaced aid for other health issues? Health Policy and Planning. 2008; $23: 2$.

5. Sridhar D: Seven challenges in international development assistance for health and ways forward. The Journal of law, medicine \& ethics. $2010 ; 38: 3$. 
6. Grepin KA: HIV donor funding has boosted and curbed the delivery of different non-HIV health services in sub-Saharan Africa. Health Affairs. $2012 ; 31: 1$.

7. NASA: HIV/AIDS expenditure by funding sources in Nigeria, 2017 \& 2018. https://naca.gov.ng/wp-content/uploads/2020/07/NASA-Report-2019.pdf 2020 accessed January 22, 2021.

8. Chima CC, Franzini L: Spillover effect of HIV-specific foreign aid on immunization services in Nigeria. Journal of International Health. 2016; 8(2).

9. Dionne KY, Gerland P, Watkins S: AIDS exceptionalism: another constituency heard from. AIDS Behav; 2013.

10. Whiteside A, Smith J: Exceptional epidemics: AIDS still deserves a global response. Global Health. 2009; 5:15.

11. Samb B, Evans T, Dybul M, Atun R, Moatti J-P, et al. An assessment of interactions between global health initiatives and country health systems. Lancet. $2009 ; 373: 9681$.

12. Biesma RG, Brugha R, Harmer A, Walsh A, Spicer N, Walt G: The effects of global health initiatives on country health systems: a review of the evidence from HIV/AIDS control. Health Policy and Planning. 2009; (24):23.

13. UNAIDS. World AIDS Day report 2017: Data book. Accessed from https://www.unaids.org/en/resources/documents/2017/2017_data_book on March 20, 2021.

14. Yu D, Souteyrand Y, Banda MA, Kaufman J, Perriëns JH: Investment in HIV/AIDS programs: does it help strengthen health systems in developing countries? Global Health. 2008; 4:8.

15. Lordan G, Tang KK, Carmignani F: (2011): Has HIV/AIDS displaced other health funding priorities? Evidence from a new dataset of development aid for health. Journal of Soc Sci Med, 2011; 3: 351-355.

16. Andrew N: Foreign aid and development in Africa; what the literature says and what the reality is. Journal of African Studies and Development. 2009, 1 : $008-015$.

17. Rabkin M, El-Sadr WM, De Cock KM: Bellagio HIV Health Systems Working Group1. The impact of HIV scale-up on health systems: a priority research agenda. J Acquir Immune Defic Syndr. 2009, 52: 6-11.

18. Smith DJ: AIDS NGOS and corruption in Nigeria. Journal of Health \& Place. 2012; 3: $475-480$.

19. Wonodi C: Overcoming barriers to routine immunization in Nigeria. http://www.jhsph.edu/research/centers-and institutes/ivac/IVACBlog/Overcoming_Barriers_to_Routine_Immunization_in_Nigeria accessed February 12, 2021.

20. Itiola AJ, Agu KA: Country ownership and sustainability of Nigeria's HIV/AIDS Supply Chain System: qualitative perceptions of progress, challenges and prospects. Journal of Pharm Policy Pract. 2018; 11: 21.

21. Jeetoo: Spillover effects in public healthcare expenditure in Sub-Saharan Africa: A spatial panel analysis. 2020, 2: 257 - 268.

22. Sachs JD: From millenium development goals to sustainable development goals. Lancet 2012; 379: 2206 - 2211.

23. Ibeneme S, Ongom M, Ukor N, Okeibunor J: Realigning Health Systems Strategies and Approaches; What Should African Countries Do to Strengthen Health Systems for the Sustainable Development Goals? Front Public Health. 2020; 8:372. doi: 10.3389/fpubh.2020.00372.

24. Chima CC, Homedes N: Impact of global health governance on country health systems; the case of HIV initiatives in Nigeria. Journal of Global Health. $2015 ; 5: 1$.

25. Kotsadam A, Gundrun $\varnothing$, Siri AS, Andreas FT, Henrik U: Development aid and infant mortality. Micro-level evidence from Nigeria. World Development. 2018; 105: 59 - 69. doi:10.1016/j.worlddev.2017.12.022.

26. Marty R, Dolan CB, Leu M, Runfola D: Taking the health aid debate to the subnational level: The impact and allocation of foreign health aid in Malawi. British Medical Journal Global Health. 2017; 2(1). doi: 10.1136/bmjgh-2016-000129.

27. Odokonyero T, Marty R, Muhumuza T, ljjo A, Moses GO: The impact of aid on health outcomes in Uganda. Health Econ. $2018 ; 4: 733$ - 745.

28. MEASURE DHS - Demographic and Health Survey (DHS). DHS overview. 2018. Retrieved from http://www.measuredhs.com/What-We-Do/SurveyTypes/DHS.cfm Accessed June, 21, 2021.

29. WHO: WHO vaccine-preventable diseases: monitoring system. 2020 global summary. 2020. https://apps.who.int/immunization_monitoring/globalsummary/estimates?c=NGA. Accessed June 18, 2020

30. World Bank: Development indicators. Data Bank. 2017. Retrieved from http://www.data.worldbank.org/indicator. Accessed on June 8, 2021

31. WHO: WHO vaccine-preventable diseases: monitoring system. 2020 global summary.

2020. https://apps.who.int/immunization_monitoring/globalsummary/estimates?c=NGA. Accessed May 18, 2020.

32. WHO: What is Integrated Management of Childhood IIInesses (IMCI)?

2020 https://www.who.int/maternal_child_adolescent/child/imci/background/en/. Accessed March 21, 2021.

33. UK Aid: Leaving no one behind? Considering the impacts of donor transition.

2017, https://www.results.org.uk/sites/default/files/files/Leaving\%20no\%20one\%20behind\%3F\%20Considering\%20the\%20Impact\%20of\%20Donor\%20Tr May 28, 2020.

34. WHO: Global health observatory data repository. Health expenditure ratios data by country, 2020 http://apps.who.int/gho/data/node.main.75? lang=en. Accessed 11 June 2021.

35. Buxton R: Statistics; Multilevel modelling. 2008. https://www.statstutor.ac.uk/resources/uploaded/multilevelmodelling.pdf. Accessed January 22 , 2021.

36. Immunization source funding for years

https://extranet.who.int/countryplanningcycles/sites/default/files/planning_cycle_repository/nigeria/nigeria_cmyp_2016-2020.pdf. Accessed March 23, 2021. 
37. Uzochukwu BSC, Chukwuogo O, Onwujekwe OE: Financing Immunization for results in Nigeria: who funds, who disburses, who utilizes, who accounts? Financing bottlenecks and accountability challenges. Afr J Health Econ 2014; 8:1.

38. WHO: NERICC-Nigeria's panacea to routine immunizatio and primary health care strengthening. 2019. https://www.afro.who.int/news/nericc-nigeriaspanacea-routine-immunization-and-primary-health-care-strengthening. Accessed April 11, 2021.

39. Arregoces L, Daly F, Pitt C, Hsu J, Martinez-Alvarez M, Greco G, Mills A, Berman P, Borghi J: Countdown to 2015: changes in official development assistance to reproductive, maternal, newborn, and child health, and assessment of progress between 2003 and 2012. The Lancet: Global Health volume. 2015; 3:7.

40. WHO: Leave no one behind: Stregthening health systems for UHC and the SDGs in Africa. 2017, https://www.afro.who.int/publications/leave-no-onebehind-strengthening-health-systems-uhc-and-sdgsafrica\#: :text=Publications-,Leave\%20no\%20one\%20behind\%3A\%20Strengthening\%20health\%20systems\%20for,and\%20the\%20SDGs\%20in\%20Africa\&te Accessed March 28, 2021

\section{Figures}

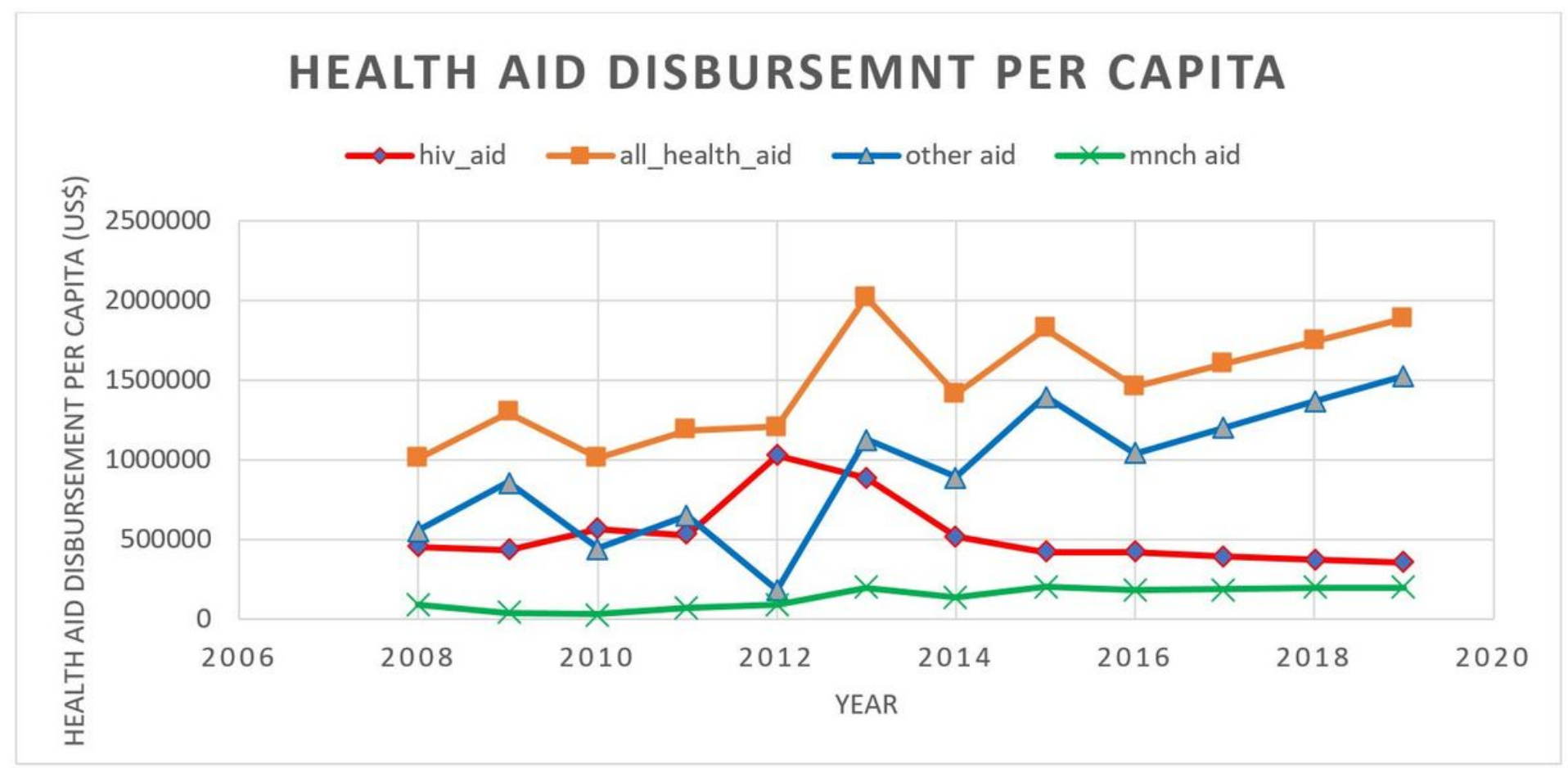

Figure 1

Health aid disbursement per capita for HIV and other health programs 


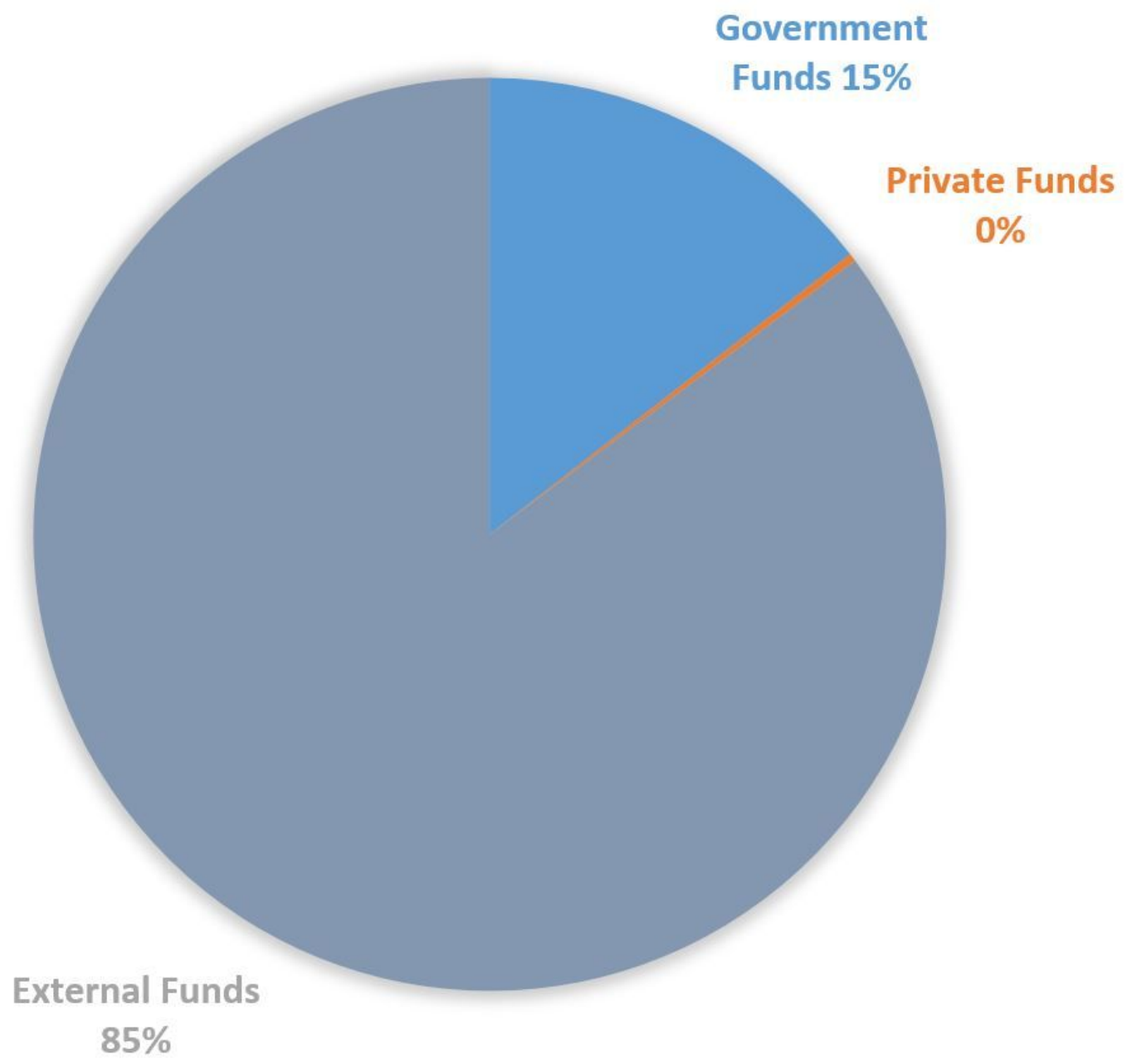

Figure 2

HIV/AIDS expenditure by funding sources in Nigeria, 2017 \& 2018. Source: National AIDS Spending Assessment (NASA) for the period $20017-2018$ [7]. 


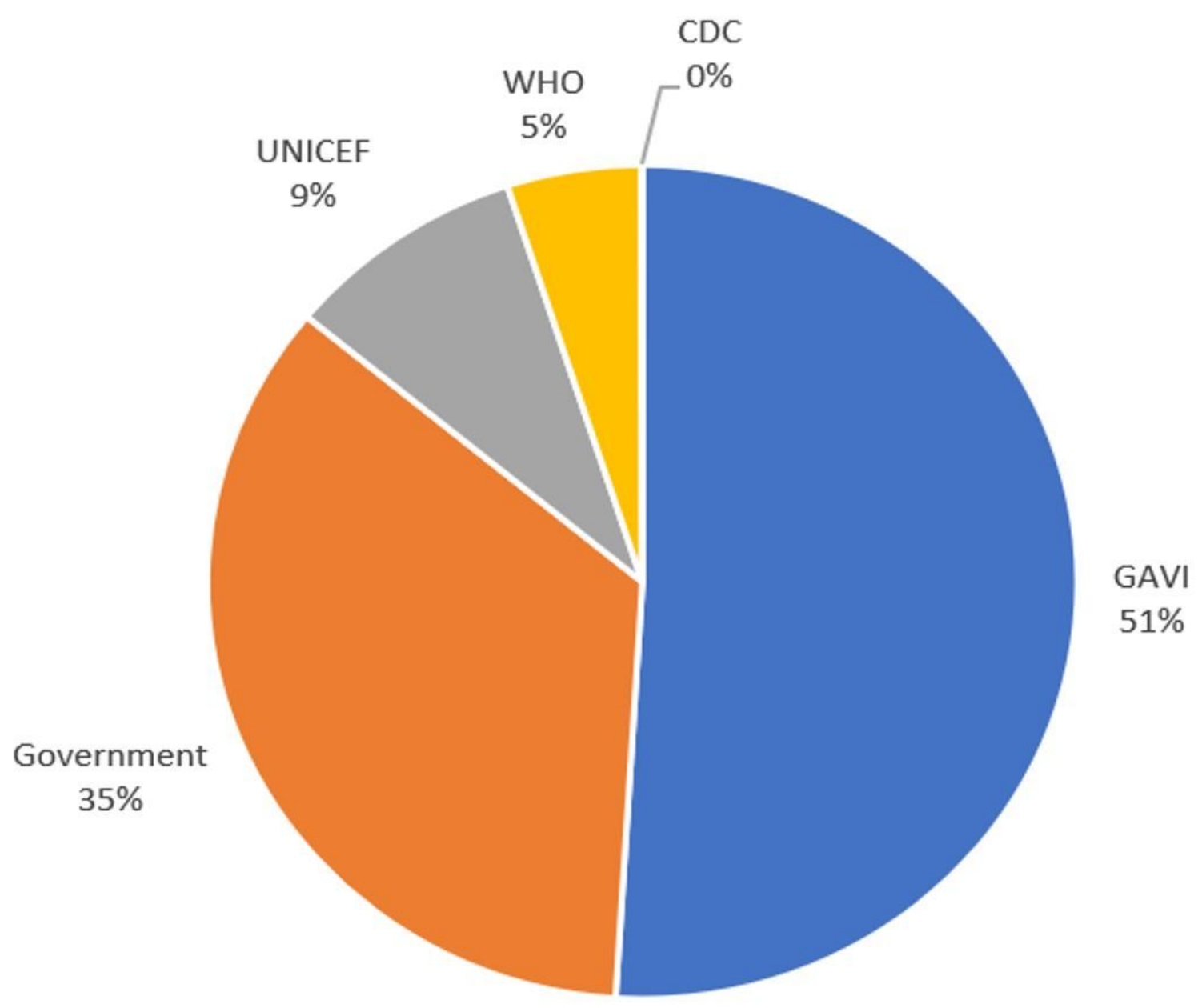

\section{Figure 3}

Expenditure for routine immunization by funding sources in Nigeria, 2020. Source: Nigeria Comprehensive Multi Year Plan, costing and financing tool [36].

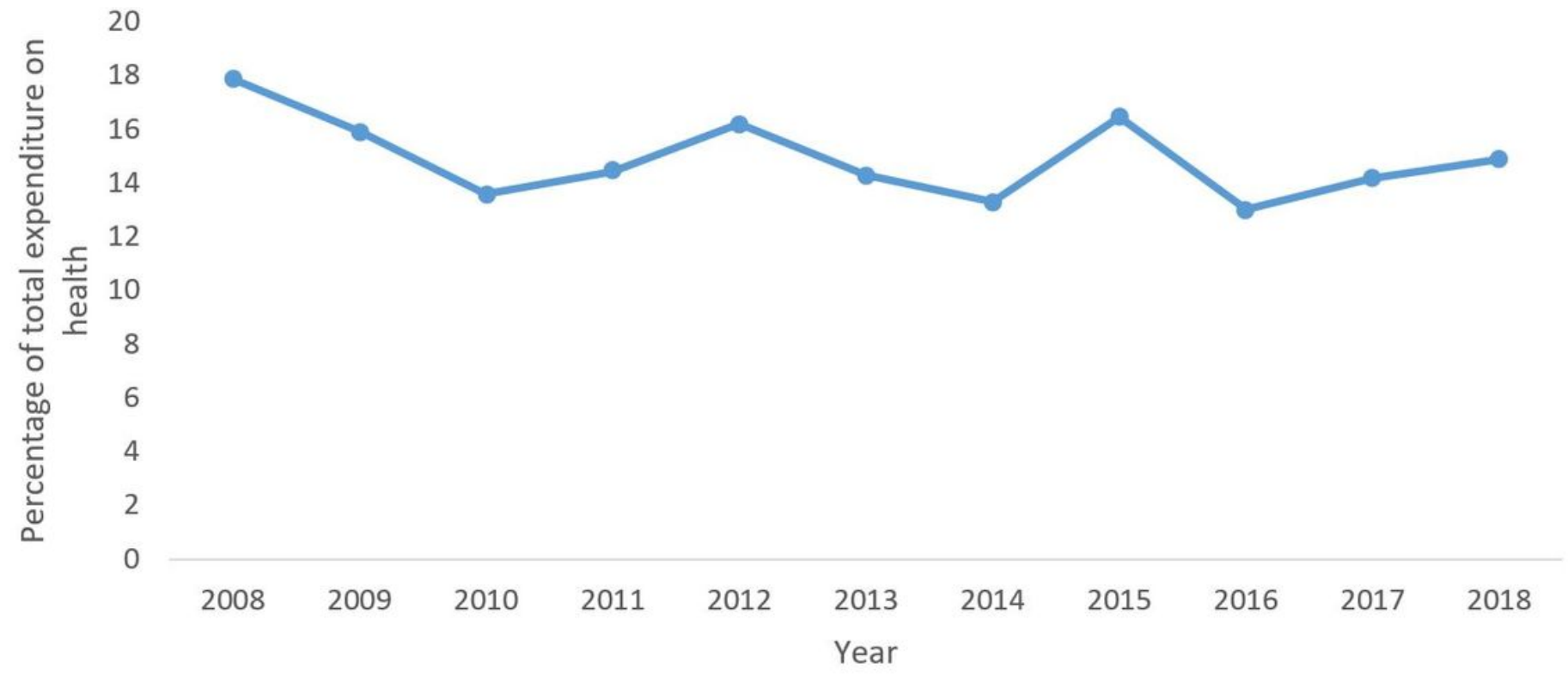


General government expenditure on health as a percentage of total expenditure on health in Nigeria, 2008 - 2018. Source: WHO Global health observatory data repository: Health expenditure ratios data by country [34].

\section{Supplementary Files}

This is a list of supplementary files associated with this preprint. Click to download.

- SupplementaryMaterial.docx 